\title{
Helminths in South Africa: management of cestode and trematode infections in humans
}

\section{RL van Zyl}

Pharmacology Division, Department of Pharmacy and Pharmacology, School of Therapeutic Sciences, Faculty of Health Sciences University of Witwatersrand, South Africa

Corresponding author, email: Robyn.vanZyl@wits.ac.za

Sub-Saharan Africa has to contend with many challenges, including inadequate healthcare systems, lack of optimal sanitation, and clean water and food. All of these contribute to malnutrition and an increased risk of infections, including parasitism by cestodes and trematodes. Schistosomiasis is a category-2 notifiable trematode (fluke) infection, whereas cestode (tapeworm) infections need not be reported to the South African Department of Health. Epidemiological data for helminthiasis in South Africa is scant, with a paucity of publications on the South African scenario. As such, a complete picture of the impact of helminth infections on all age groups in South Africa does not exist. These parasitic diseases not only have an impact on socio-economic development of a country, community and families, but also contribute to the chronic and detrimental effects on the health and nutritional status of the host, including the impaired development of children. In order to break the cycle of poverty and disease, a strong education drive is required in schools and communities to provide effective strategies and guidelines on preventative measures that result in avoidance of exposure to infective stages of Schistosoma and Taenia tapeworms. Also, it is imperative that healthcare professionals are able to recognise the signs and symptoms, so that interventions can be promptly initiated. The current anthelmintic treatments available in South Africa are effective against cestodes and trematodes, with no drug resistance having being reported. The need for compliancy when taking anthelmintic drugs must be emphasised.

Keywords: helminths, tapeworm, bilharzia, treatment, South Africa

\section{Introduction}

Being infected with helminth parasites is a way of life for those living in tropical and sub-tropical climates, where recognition of the associated signs and symptoms and control of environmental factors are essential to reduce infection rates. Listed as Neglected Tropical Diseases (NTDs), taeniasis/cysticercosis and schistosomiasis are a diverse group of communicable diseases that are prevalent in tropical/subtropical countries. ${ }^{1}$ They cause substantial illness in more than one billion people throughout the world, particularly in underdeveloped countries and in persons with comorbidities. ${ }^{1}$ Several factors contribute to the high prevalence of these helminth infections, such as malnutrition, unclean food/water, lack of adequate sanitation and close contact with infectious vectors, domestic animals and/ or livestock. In addition, the lack of education, poor recognition of asymptomatic infections and neglect by health authorities, all contribute to the large number of cases around the world, where millions of people harbour worms at any one time. ${ }^{1,2}$ Compared to other diseases such as malaria, helminthiasis is rarely a cause of death. However, helminths do contribute to chronic bad health and deleterious effects on the nutritional status of the host. Moreover, their presence can impair the development of children and affect the course and outcome of pregnancy. ${ }^{3}$ Helminths can limit productivity, resulting in a cycle of poverty and disease that restricts a country's growth. ${ }^{1}$ In sub-Saharan Africa, many communicable, maternal, neonatal and nutritional disorders remain the dominant cause of a high disease burden. ${ }^{2}$
A 2010 disability-adjusted life years (DALY) study showed that the highest rates of NTDs (excluding malaria) were in central sub-Saharan Africa, largely due to the combined prevalence of schistosomiasis, onchocerciasis, African trypanosomiasis and hookworm. ${ }^{2}$

\section{Helminth groups}

The word 'helminth' is derived from the Greek 'helmins' meaning 'parasitic worm'. Helminths have co-evolved with specific mammalian and a wide range of vertebrate and invertebrate hosts. There is strict host specificity at the species level, as far as the definitive host is concerned (the host in which sexual reproduction of the parasite occurs). Helminths that preferentially infect humans are mainly nematodes (roundworms), cestodes (tapeworms) and trematodes (flukes). ${ }^{4}$ The therapeutic management of the main cestode and trematode infections occurring in South Africa is covered in this article (Table I).

\section{Trematodes}

Schistosomiasis also known as bilharzia, 'snail fever', or Katayama fever (acute phase of schistosomiasis) is a waterborne trematode parasitic disease that is transmitted by freshwater snails in dams, lakes and rivers as the intermediate host. ${ }^{5}$ The WHO estimated that in 2017, 220.8 million people required preventative treatment in 78 tropical/sub-tropical countries, with $92 \%$ living in Africa, and the disease resulted in approximately 200000 deaths globally. ${ }^{6,7}$ Preventative treatment repeated over 
a number of years, was proposed to help reduce and prevent morbidity. ${ }^{7}$ However, communities in only 52 endemic countries with moderate-to-high transmission were targeted for largescale treatment, with 102.3 million people reportedly having received preventative treatment. ${ }^{7}$ Bilharzia is endemic in certain parts of South Africa, with approximately 4 million at risk of $S$. mansoni or S. haematobium infection. ${ }^{8}$

The susceptible population groups include those who bath, wash laundry or swim in warm, slow-moving fresh water. During exposure, cercariae that have been shed by snails penetrate the skin; possibly causing a transient, pruritic papular rash or 'swimmer's itch'. Worms develop to the adult stage in the human host in 6-12 weeks (Table I). ${ }^{9}$ The female worms produce eggs, most of which are excreted in the urine/faeces. If eggs end up in bodies of water, they hatch, and the larval stages infect snails to begin the life cycle again. ${ }^{10}$ However, some eggs remain in various human tissues to cause initial, acute symptoms namely, fever, chills, wheezing, headache, cough and urticaria (Katayama disease), and patients characteristically present with eosinophilia. ${ }^{8}$ The eggs cause chronic inflammation and longterm tissue damage in the infected organs. S. haematobium eggs may lodge in the kidney and bladder, increasing the risk of bladder cancer. S. haematobium frequently causes lesions in the female reproductive tract. When S. mansoni eggs are trapped in the intestinal wall, thickening results in fibrosis with possible bleeding (Table I). Female urogenital schistosomiasis remains undiagnosed in most cases and is associated with a risk of HIV and HPV infections. ${ }^{11}$ As with ascariasis, children with a chronic schistosome infection can suffer from anaemia and malnutrition that can result in school absenteeism and learning disabilities. Optimal therapy needs to be initiated as soon as a diagnostic confirmation is obtained (Table I). Non-schistosome trematode infections are very rarely diagnosed in South Africa and are not considered here.

\section{Cestodes}

Cestodes are tapeworms that reside in the intestinal lumen following, mainly, the ingestion of parasite eggs, raw or undercooked meat and fish containing larval cysts. Cestodes that frequently infect humans are Taenia saginata (beef tapeworm), Hymenolepis nana (dwarf tapeworm), and T. solium (pork tapeworm), along with Echinococcus granulosus (hydatid worm found in dogs). Diphyllobothrium latum (fish tapeworm) does not occur in South Africa, whilst Dipylidium caninum (flea tapeworm) infect humans on rare occasions. The clinical syndromes caused by $T$. solium are categorised as either taeniasis (intestinal tapeworm infection) or cysticercosis (cysts in brain, muscle and other tissues).${ }^{10}$ Ingested tapeworm larvae attach to the intestinal tract via the scolex (head); whilst, cysticercosis can develop if the $T$. solium oncospheres from ingested eggs enter extra-intestinal tissue and cross the blood-brain-barrier. ${ }^{4}$ The cysticerci (mature oncespheres) cause life-threatening neurocysticercosis, whilst apparently remaining undetected by the host's immune system due to the release of a variety of compounds/enzymes by the cysticerci. ${ }^{12}$ Eventually the parasite dies and degrades, thereby promoting an inflammatory response that can initiate an acute onset of seizures in both adults and children. This potential outcome necessitates that all family members be tested for tapeworm infections, so as to prevent transmission from occurring. ${ }^{13} \mathrm{~T}$. solium infection can place the host and others at risk of developing cysticercosis; as such it is recommended that the adult cestode be eliminated with niclosamide, albendazole, praziquantel, or mebendazole (Table II). Praziquantel and albendazole are used to treat cerebral cysticercosis, while surgery is the standard treatment before medication for ocular cysticercosis. ${ }^{14}$ Praziquantel is more effective than niclosamide against $H$. nana (Table II).

\section{Diagnosis}

Successful treatment relies on a confirmed infection and verification of helminth species. Whereas, the primary indications of an infection are mostly the presentation of clinical signs and symptoms, clinical outcomes due to a helminth infection are often unspecific and many patients are asymptomatic. ${ }^{1,15}$ Various diagnostic protocols are available for the correct identification of the helminth species (Table I). Schistosomiasis is usually diagnosed by serological techniques, which should be followed by parasitological visualisation of the eggs in the stool/urine. This is partly because an ELISA antibody test can be falsely positive if the patient has a history of having had bilharzia. ${ }^{16}$ The test can also be falsely negative because of a long seronegative window period.

\section{Pharmacological interventions}

Currently there are no vaccines to protect the community against schistosomiasis or Taenia infections, but advances are being made to vaccinate livestock to reduce the risk of infection from the primary source. ${ }^{17}$ Helminths have susceptible nervous and muscular systems that are ideal targets for pharmacological agents (Table II).

Acute schistosomiasis is treated with oral prednisolone followed by praziquantel, with treatment repeated in chronic cases (Table II). ${ }^{8}$ Praziquantel is not used prophylactically as it is ineffective against very early infections. ${ }^{6}$ When schistosomiasis and soiltransmitted helminths are co-endemic, praziquantel and albendazole/mebendazole can be safely co-administered. ${ }^{18}$ The precise mechanism of action of praziquantel remains unknown. Several mechanism have been proposed, but the action of praziquantel is limited very specifically to trematodes and cestodes (Table II). ${ }^{19}$ The emergence of resistance to praziquantel would be a setback with regards to eliminating global schistosomiasis, as it is the only affordable and effective drug for treating all forms of the disease. Fortunately, reported cases of resistance have not exhibited a high degree of resistance, nor are they widely prevalent. ${ }^{20}$ The current anthelmintic treatments available in South Africa are effective against cestodes and trematodes, with no drug resistance having been reported. As much as $10-30 \%$ of bilharzia infections may require retreatment, but not due to drug resistance (Prof. Frean, NICD).

Taenia infections are also effectively treated with praziquantel along with niclosamide, albendazole or mebendazole, which 


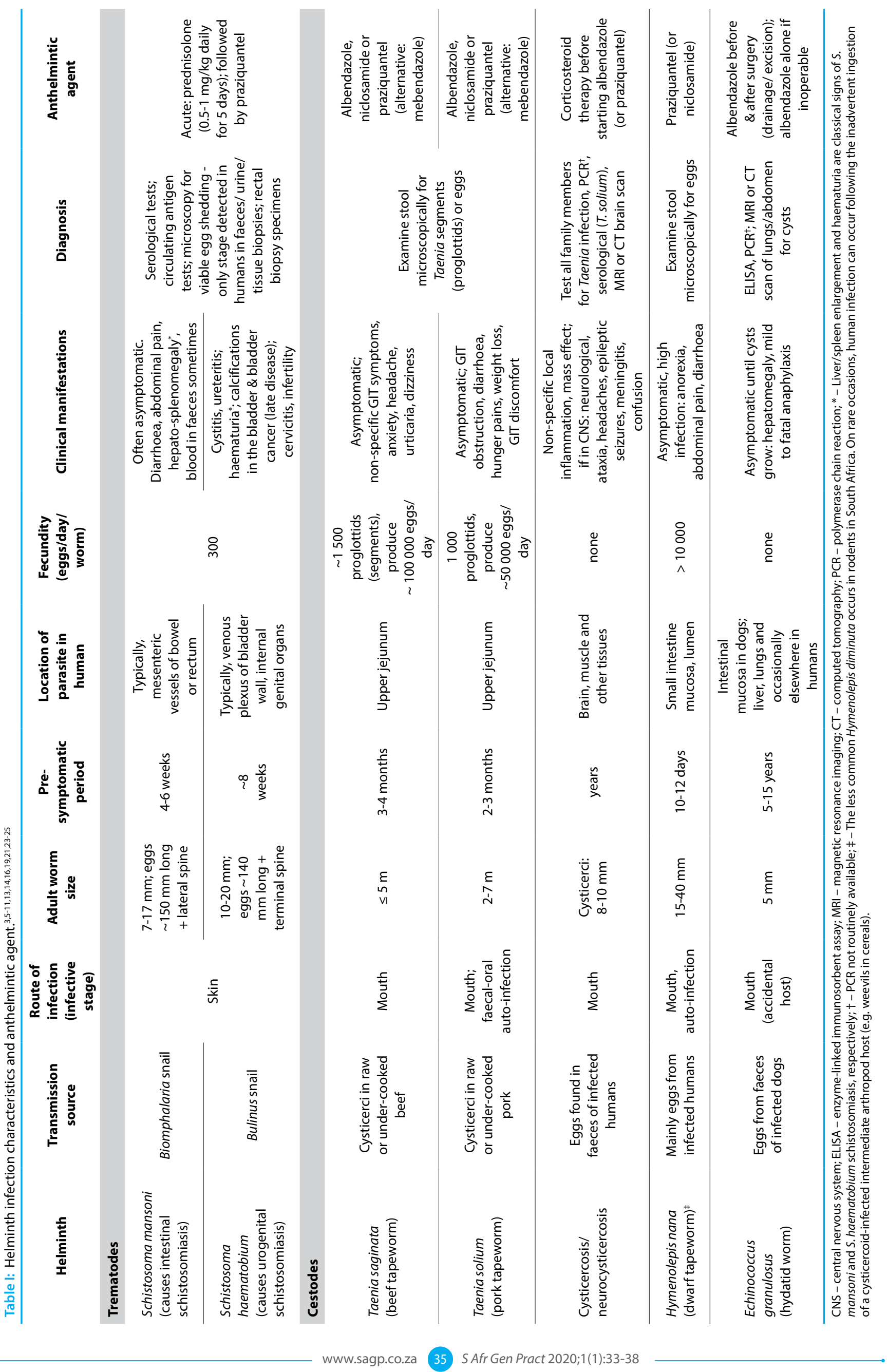



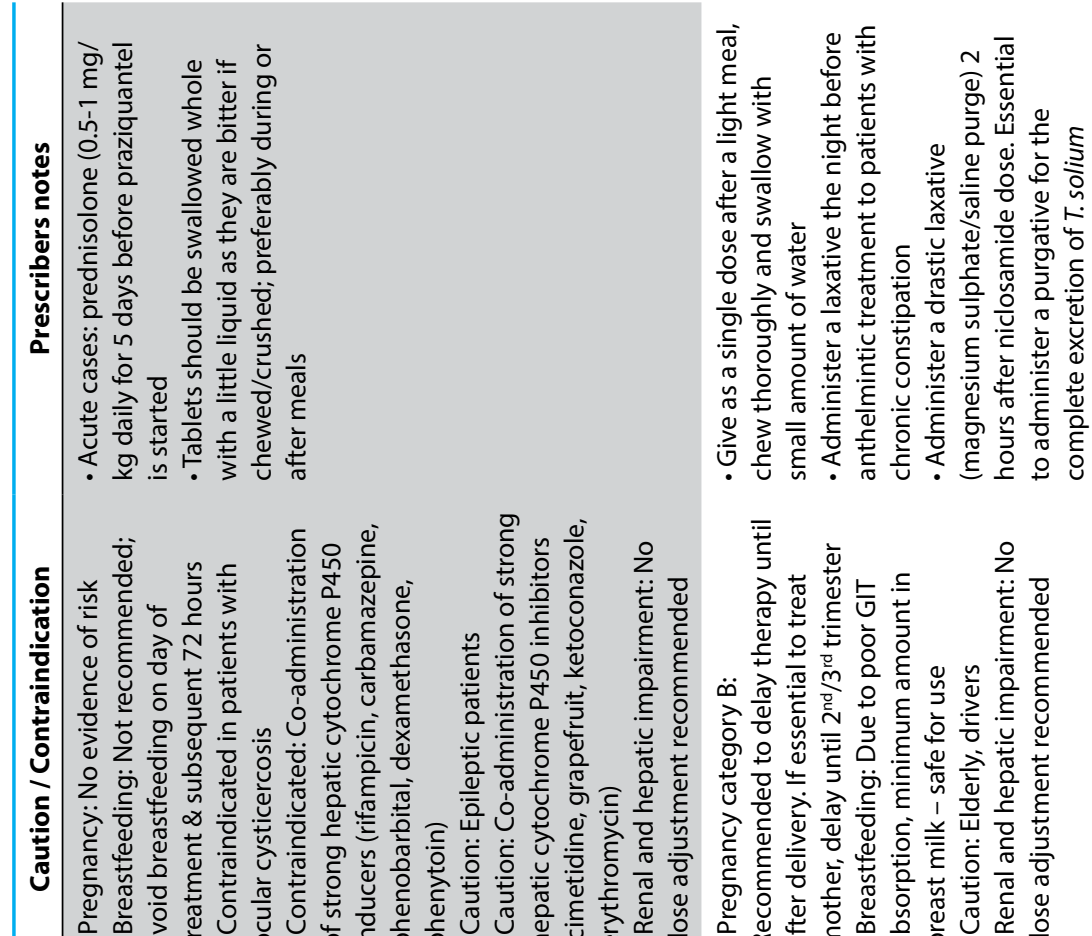

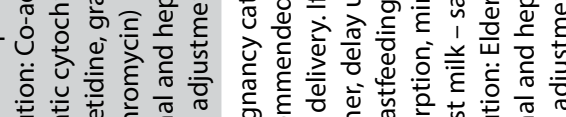

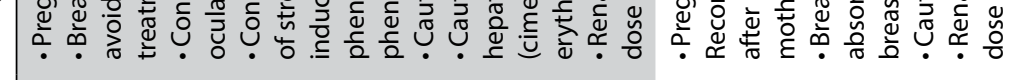
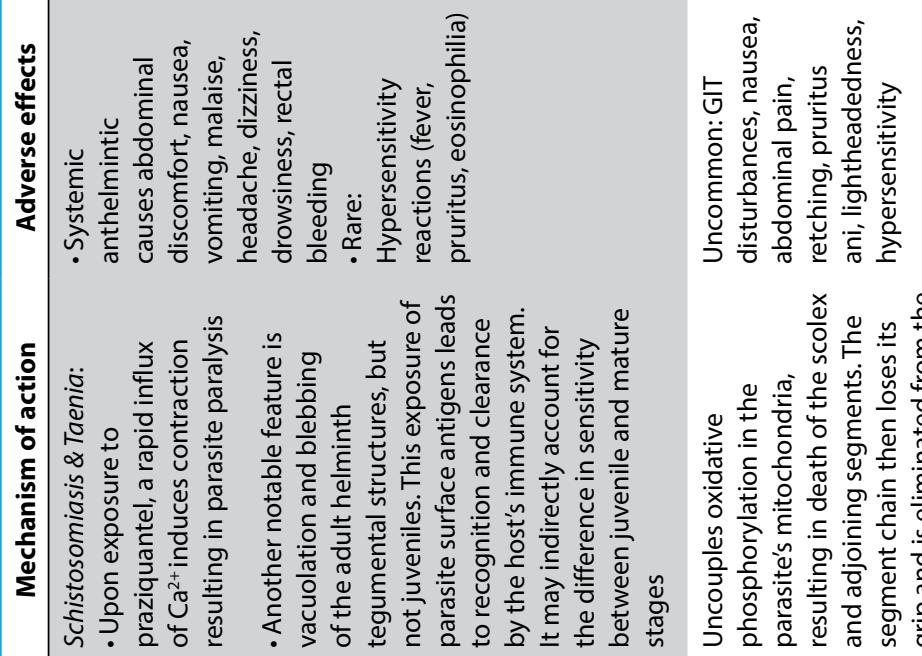

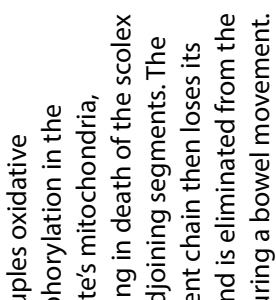

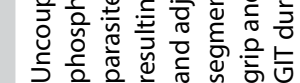

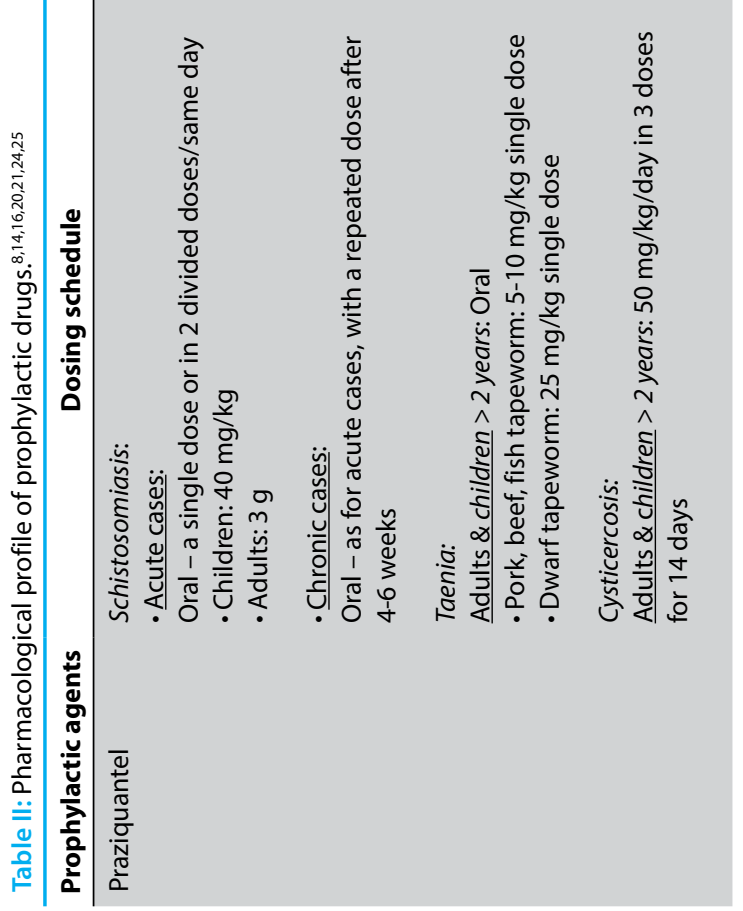

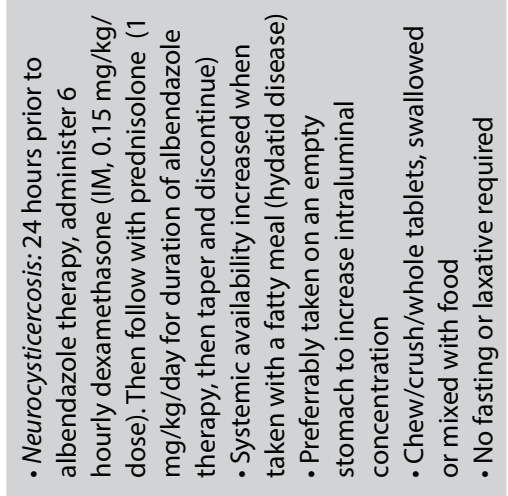

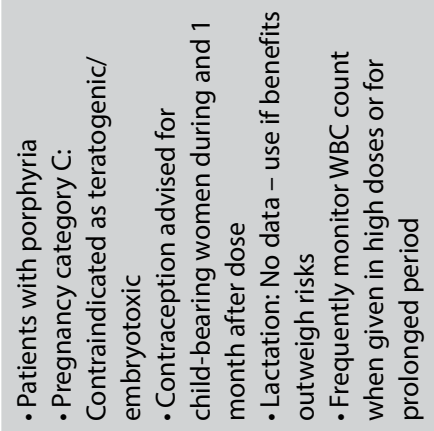

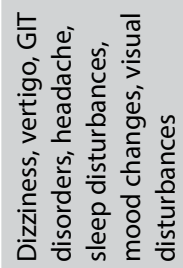

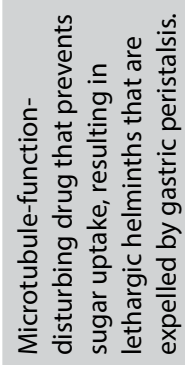

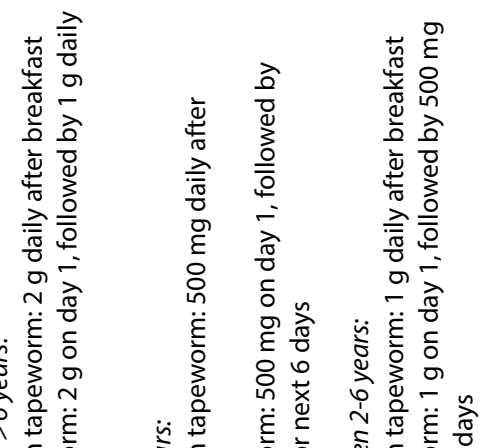

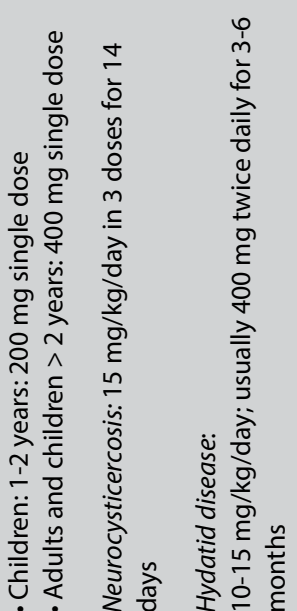




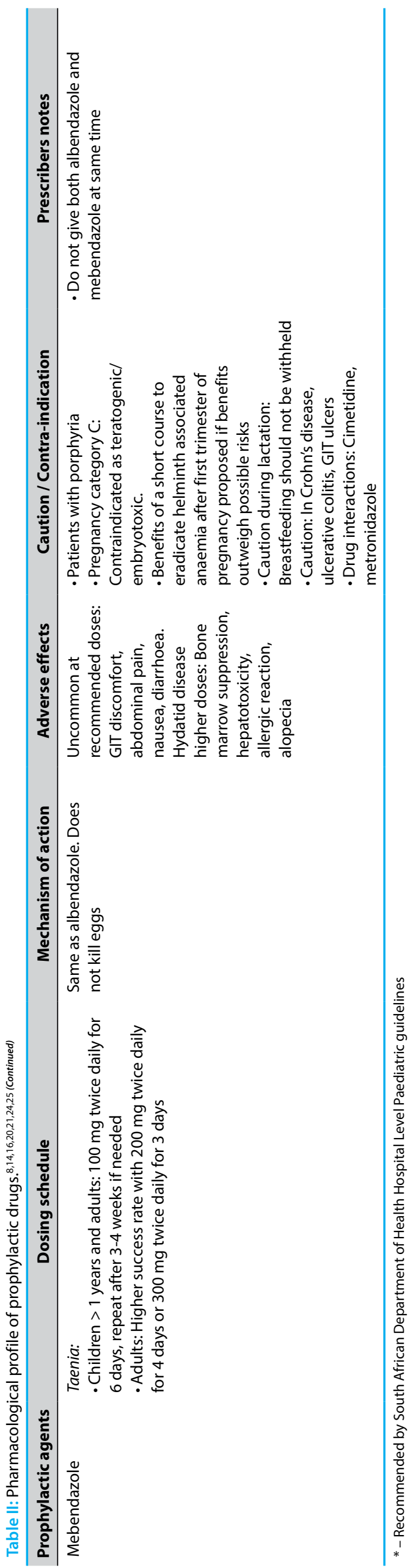

either induce paralysis or decrease energy levels within the helminth, resulting in the evacuation of the helminth from the GIT (Table II). The selective toxicity of niclosamide is explained by its poor absorption from the host's intestine, thus protecting the host cells against the drug's uncoupling properties. ${ }^{8}$ The risk of developing cysticercosis as a result of treating $T$. solium infections with niclosamide is small, provided the dosage instructions are complied with. ${ }^{14,16}$ Albendazole and mebendazole are more commonly used to treat soil-transmitted helminths, but are effective against cestodes if the instructions are followed (Table II). ${ }^{14,16} \mathrm{~A}$ combination of albendazole and praziquantel is more effective in neurocysticercosis patients with more than two cystic lesions and a longer course of combination therapy is often needed in patients with multiple subarachnoid cysticerci. Both agents may intensify the inflammatory response around the dying parasite, thereby exacerbating seizures/hydrocephalus, as such high-dose glucocorticoids should be administered. To overcome the inducing effects of glucocorticosteroids on the first-pass metabolism of praziquantel, cimetidine should be co-administered to ensure an optimal anthelmintic plasma concentration of praziquantel. ${ }^{13}$

\section{Non-pharmacological control measures}

Helminth eggs are sensitive to several disinfectants such as sodium hypochlorite and glutaraldehyde when used against T. solium, T. saginata and Schistosoma, with $70 \%$ ethanol also being effective against Schistosoma. ${ }^{22,23}$ Undercooked, smoked or pickled meat can be infective. Ways to ensure inactivation of helminths/cysticerci include irradiation, a minimum cooking temperature of $60^{\circ} \mathrm{C}$ or freezing at $-10^{\circ} \mathrm{C}$ for four days. Cysticerci can survive for up to 30 days in pork kept at $4{ }^{\circ} \mathrm{C}$ and some helminth eggs can persist in the environment for months. ${ }^{22,23}$ Untreated water from freshwater sources may contain cercariae, but schistosomiasis can be prevented if the water is poured through fine-mesh filters or chlorinated or heated to $50{ }^{\circ} \mathrm{C}$ for five minutes, or allowed to stand for $\geq 24$ hours before use. ${ }^{6}$

\section{Conclusion}

Epidemiological data for helminth infections in South Africa is scant, with a paucity of publications on the South African scenario. Even though schistosomiasis is a category-2 notifiable medical condition, statistics are not regularly available, whilst tapeworm infections need not be reported. As such, a complete picture of the impact of helminth infections on all age groups in South Africa is unavailable. To address the high infection rates predicted by the WHO, it is evident that a strong educational drive is required in schools and communities to provide effective strategies and guidelines on preventative measures to avoid exposure to Schistosoma and Taenia., ${ }^{126,27}$ Although most infections are silent, it is also imperative that healthcare professionals are able to recognise the signs and symptoms of helminth infections to facilitate prompt interventions. Lastly, compliancy should be emphasised when patients take anthelmintic drugs to ensure successful treatment to protect not only the patient, but also family members and the community. 


\section{Acknowledgements}

I wish to acknowledge Professor Miles Markus and Professor John Frean for their invaluable contributions and advice in the preparation of this manuscript. My thanks to Jabu Mahlangu, Fatima lqbal and Lehlogonolo Ramoshu for assisting me to collect information.

\section{References}

1. WHO. World Health Organisation Neglected Tropical Diseases - Summary. 2016a. Accessed August 2019. Available from: http://www.who.int/neglected_diseases/ diseases/summary/en/.

2. Murray CJL, Vos T, Lozano R, et al. Disability-adjusted life years (DALYs) for 291 diseases and injuries in 21 regions, 1990-2010: a systematic analysis for the Global Burden of Disease Study 2010. Lancet. 2012;380:2197-223.

3. Weller PF, Nutman TB. Intestinal nematode infections. In: Kasper D, Fauci A, Hauser S, Longo D, Jameson J, Loscalzo J. eds. Harrison's Principles of Internal Medicine, 19e. New York: McGraw-Hill; 2018. Accessed August 2019. Available from: https://accessmedicine.mhmedical.com/content.aspx?bookid=1130\&sect ionid $=79740918$.

4. Weller PF. Introduction to helminthic infections. In: Jameson J, Fauci AS, Kasper $\mathrm{DL}$, Hauser SL, Longo DL, Loscalzo J. eds. Harrison's Principles of Internal Medicine, 20e New York: McGraw-Hill; 2018. Accessed August 2019. Available from: https://accessmedicine.mhmedical.com/content.aspx?bookid=2129\&sect ionid $=192027508$.

5. Riedel $S$, et al. Medical Parasitology. In: Riedel S, Hobden JA, Miller S, Morse SA, Mietzner TA, Detrick B, Mitchell TG, Sakanari JA, Hotez P, Mejia R. eds. Jawetz, Melnick, \& Adelberg's Medical Microbiology, 28e. New York: McGraw-Hill; 2019. Accessed August 2019. Available from: http://accessmedicine.mhmedical.com/ content.aspx?bookid $=2629 \&$ sectionid $=217776556$.

6. Montgomery S. Centre of Disease Control Yellow Book. Chapter 4: TravelRelated Infectious Diseases. Schistosomiasis. 2019a. Accessed August 2019. Available from: https://wwwnc.cdc.gov/travel/yellowbook/2020/ travel-related-infectious-diseases/schistosomiasis.

7. WHO. Key facts on Schistosomiasis. 2019. Accessed August 2019. Available from: https://www.who.int/en/news-room/fact-sheets/detail/schistosomiasis,

8. South African Department of Health. Standard Treatment Guidelines and Essential Medicines List for South Africa. Hospital Level, Paediatrics. 2017. Accessed August 2019. Available from: http://www.health.gov.za/index.php/ component/phocadownload/category/197.

9. Vennervald B. Schistosomiasis and other trematode infections. In: Jameson J, Fauci AS, Kasper DL, Hauser SL, Longo DL, Loscalzo J. eds. Harrison's Principles of Internal Medicine, 20e. New York: McGraw-Hill. 2018. Accessed August 2019. Available from: http://accessmedicine.mhmedical.com/content.aspx?bookid=21 $29 \&$ sectionid $=192027758$.

10. CDC. Centres for Disease Control and Treatment. Schistosomiasis Infection. 2017. Accessed August 2019. Available from: https://www.cdc.gov/dpdx/ schistosomiasis/index.html.

11. WHO. Female Genital Schistosomiasis: A Pocket Atlas For Clinical Health-Care Professionals. 2015. Accessed August 2019. Available from: http://apps.who.int/ iris/bitstream/10665/180863/1/9789241509299_eng.pdf?ua=1
12. Romano $M C$, Jiménez $P$, Miranda-Brito $C$, Valdez RA. Parasites and steroid hormones: corticosteroid and sex steroid synthesis, their role in the parasite physiology and development. Front Neurosci. 2015;30 June:1-5. https://doi. org/10.3389/fnins.2015.00224.

13. White Jr A, Weller PF. Cestode Infections. In: Jameson J, Fauci AS, Kasper DL, Hauser SL, Longo DL, Loscalzo J. eds. Harrison's Principles of Internal Medicine, 20e. New York, NY: McGraw-Hill. 2018. Accessed August 2019. Available from: https://accessmedicine.mhmedical.com/content.aspx?bookid=2129\&sectio nid=192027850.

14. Rossiter D. South African Medical Formulary (SAMF) 12th Edition. Chapter P02: Anthelmintics. In: Rossiter D, ed. South African Medicines Formulary. Cape Town: Health and Medical Publishing Group; 2016:528-533.

15. McCarthy JS, Moore TA. Drugs for helminths. Mandell, Douglas, and Bennett's Principles and Practice of Infectious Diseases, Updated Edition, Elsevier; 42, 519-527.e4 2015. Accessed August 2019. Available from: https://www.clinicalkey. com/\#!/content/book/3-s2.0-B9780323401616000425.

16. South African Department of Health. EML Clinical Guide Mobile Application. 2014.

17. Sumbria D, Singla LD. Mammalian parasitic vaccine: A consolidated Exposition. J Vaccines Immun. 2015;1:050-059.

18. Namwanje $H$, Kabatereine NB, Olsen $A$. The acceptability and safety of praziquantel alone and in combination with mebendazole in the treatment of Schistosoma mansoni and soil-transmitted helminthiasis in children aged 1-4 years in Uganda. Parasitol. 2011;138:1586-1592.

19. Cupit PM, Cunningham $C$. What is the mechanism of action of praziquantel and how might resistance strike? Future Med. Chem. 2015;7:701-705.

20. Vale N, Gouveia MJ, Rinaldi G, et al. Praziquantel for schistosomiasis: singledrug metabolism revisited, mode of action, and resistance. Antimicrob Agents Chemother. 2017;61:e02582-16.

21. Montgomery S. Centre of Disease Control Yellow Book. Chapter 4: Travel-Related Infectious Diseases. Taeniasis. 2019b. Accessed August 2019. Available from: https://wwwnc.cdc.gov/travel/yellowbook/2020/ travel-related-infectious-diseases/taeniasis.

22. Spickler AR. Taenia Infections. 2005. Accessed August 2019. Available from: http://www.cfsph.iastate.edu/Factsheets/pdfs/taenia.pdf.

23. Public Health of Canada. Pathogen Safety Data Sheets: Infectious Substances Taenia solium. Accessed August 2019. Available from: https://www.canada.ca/ en/public-health/services/laboratory-biosafety-biosecurity/pathogen-safetydata-sheets-risk-assessment/taenia-solium.html.

24. EMGuidance, 2017. Accessed August 2019. Available from: https://emguidance. com/.

25. Utzinger J, Becker SL, Knopp S, et al. Neglected tropical diseases: diagnosis, clinical management, treatment and control. Swiss Med Wkly. 2012;142:w13727.

26. Fincham JE, Markus MB, Appleton CC, et al. Complications of worm infestation Serious, costly, predictable and preventable. SAMJ. 1998;August:952-953.

27. WHO Integrating Neglected Tropical Diseases Into Global Health And Development. 2017. Accessed August 2019. Available from: https://apps.who. int/iris/bitstream/handle/10665/255011/9789241565448-eng.pdf;jsessionid=32 EE4F2C5056DCCA2033443E46ADD977?sequence=1. 